\title{
ALTERNATIVAS DE SELEÇÃO EM POPULAÇÃO \\ DE MARACUJAZEIRO-AZEDO SOB SELEÇÃO RECORRENTE INTRAPOPULACIONAL ${ }^{1}$
}

\author{
MARCELO GERALDO DE MORAIS SILVA² \& ALEXANDRE PIO VIANA ${ }^{3}$
}

RESUMO- Em programas de melhoramento, é comum a avaliação de muitas características com o objetivo de praticar a seleção em várias delas, simultaneamente, com o objetivo de se obterem genótipos uniformes para as várias características sob seleção. Uma alternativa para viabilizar esta técnica é o uso dos índices de seleção, que utilizam técnicas multivariadas para associar informações relativas a vários caracteres de interesse agronômico com as propriedades genéticas da população avaliada. Assim, o objetivo deste trabalho foi predizer o progresso esperado com a seleção por meio de diferentes índices de seleção multivariados. Foram plantadas, em outubro de 2007, 140 progênies de irmãos completos de maracujazeiro-azedo, em delineamento látice quadrado, com duas repetições, e parcelas constituídas de três plantas. Foram avaliados onze caracteres. Os índices multivariados não paramétricos de Mulamba e Mock e o Índice da distância Genótipo-Ideótipo permitiram predizer ganhos superiores e de forma equilibrada entre as características, quando comparados com os índices paramétricos de Smith e Hazel, e Pesek e Baker. Utilizando os índices não paramétricos, foi possível selecionar progênies superiores para a maioria das características, simultaneamente, dando continuidade ao programa de melhoramento regional em execução.

Termos para a indexação: Passiflora edulis, índices multivariados, variabilidade, resposta à seleção.

\section{ALTERNATIVES OF SELECTION IN A YELLOW PASSION FRUIT POPULATION UNDER INTRAPOPULATION RECURRENT SELECTION}

\begin{abstract}
In breeding programs, it is common to the assessment of many traits in order to practice selection in several of them simultaneously, in order to obtain uniform genotypes for defferent traits under selection. A viable alternative to this technique is the use of selection indices, using multivariate techniques to associate information about various traits of agronomic interest with the genetic properties of the studied population. The objective of this study was to predict the expected progress with selection by means of different multivariate selection indices. Were planted in October 2007, 140 full-sib progenies of passion fruit in square lattice design with two replications and plots consisting of three plants. We evaluated eleven characters. The non-parametric multivariate indices Mulamba and Mock and index the distance Genotypeideotype, allowed to predict higher earnings and a balanced way between the characteristics when compared with the parametric indices of Smith and Hazel and Pesek and Baker. Using non-parametric indices was possible to select superior progenies for most traits simultaneously continuing the regional improvement program running.
\end{abstract}

Index terms: Passiflora edulis, multivariate index, variability, response to selection.

${ }^{1}$ (Trabalho 182-11). Recebido em: 27-06-2011. Aceito para publicação em: 10-04-2012.

${ }^{2}$ Instituto Federal do Norte de Minas, Fazenda São Geraldo, S/N, Km 06. CEP: 39480-000, Januária-MG. E-mail: mcoro2003@yahoo.com.br ${ }^{3}$ Universidade Estadual do Norte Fluminense Darcy Ribeiro - UENF, Av: Alberto Lamego, 2000, Parque California, Campos dos Goytacazes-RJ. CEP: 28013-610,.E-mail: pirapora@uenf.br 


\section{INTRODUÇÃO}

O Brasil ocupa o posto de terceiro maior produtor mundial de frutas, superado somente pela China e Índia. Dentro desse cenário, estimativas do IBGE (2010) apontam o Brasil como o maior produtor de maracujá-azedo (Passiflora edulis Sims), com produção em torno de 718 mil toneladas.

A avaliação de componentes da produção, como o número de frutos e a produtividade, é essencial no melhoramento genético de espécies perenes. Entretanto, no maracujazeiro, além dessas características, a qualidade dos frutos é também de suma importância, por determinar a aceitação do produto e ter influência direta no preço obtido em sua comercialização. A qualidade do fruto é um termo amplo que engloba dimensões e peso do fruto, polpa e outras propriedades para as quais o consumidor ou a indústria são sensíveis (ALBUQUERQUE et al., 2002).

Na condução de um programa de melhoramento genético vegetal, é comum a avaliação de vários caracteres com o objetivo de praticar a seleção em alguns deles, simultaneamente. Nesse aspecto, o genótipo selecionado deve reunir, ao mesmo tempo, uma série de atributos favoráveis capazes de satisfazer as exigências do produtor ou consumidor.

O uso dos índices de seleção é uma ótima alternativa para a obtenção de respostas e ganho de seleção para mais de um caráter, simultaneamente, permitindo obter genótipos com padrões adequados para diversas caraterísticas de forma mais rápida do que a seleção truncada. Associado a isto, a seleção baseada em um ou poucos caracteres pode gerar alterações indesejáveis em outras, devido a correlações genéticas negativas entre elas.

Os índices de seleção têm sido utilizados como alternativas de seleção em várias espécies vegetais, como milho comum (TARDIN et al., 2007), milho-pipoca (FREITAS JÚNIOR et al., 2009), soja (VASCONCELOS et al., 2008), cana-de-açúcar (PEDROZO et al., 2009), maracujá (OLIVEIRA et al., 2008, SILVA et al., 2009), dentre outras.

O índice de seleção é a combinação linear de valores fenotípicos de um genótipo, o qual resulta numa medida que concentra, num único valor, os méritos e deméritos de cada genótipo para vários caracteres (GARCIA; SOUZA JÚNIOR, 1999). Entre os índices de seleção disponíveis para utilização, encontram-se os não paramétricos ou não lineares, que não levam em consideração nenhum parâmetro populacional em sua composição, e os chamados índices paramétricos ou lineares, pois levam em sua composição medidas de parâmetros populacionais em combinação linear para sua estimação.

Neste contexto, o objetivo deste trabalho foi avaliar o progresso genético predito por diferentes índices de seleção multivariados, paramétricos e não paramétricos, em uma população de maracujá-azedo sob seleção recorrente intrapopulacional, composta por 140 progênies de irmãos completos.

\section{MATERIAL E MÉTODOS}

Foram utilizadas 140 progênies de irmãos completos de maracujazeiro-azedo. Estas progênies foram obtidas de cruzamentos dirigidos da população melhorada ( $\mathrm{MA}_{1}$ ), estruturada em delineamento estatístico, ou seja, das 26 progênies de meios-irmãos avaliadas previamente, foram feitos cruzamentos apenas entre as 18 melhores para a obtenção das progênies de irmãos germanos. Mais detalhes sobre a população e a metodologia para sua obtenção estão descritos em Silva et al. (2009).

O plantio foi realizado em outubro de 2007 , no delineamento em látice quadrado, com duas repetições e parcelas constituídas de três plantas. $\mathrm{O}$ experimento foi instalado na área experimental da Escola Agrícola Antônio Sarlo, no município de Campos dos Goytacazes, região norte do Estado do Rio de Janeiro, com latitude sul de $21^{\circ} 45^{\prime}$, longitude $41^{\circ} 20^{\prime} \mathrm{W}$ e $11 \mathrm{~m}$ de altitude.

O sistema de condução foi o de espaldeira vertical, com mourões de eucalipto tratado de $2,5 \mathrm{~m}$ de altura, espaçados de quatro metros e com um fio de arame número 12 a 1,80 m do solo. A distância entre linhas de plantio foi de $3,5 \mathrm{~m}$, a fim de possibilitar a mobilização de máquinas dentro do experimento. Os tratos culturais foram os recomendados para a cultura (VIANA et al., 2003).

Foram avaliados os seguintes caracteres de acordo com metodologia descrita em Silva et al., (2009): número de dias para o florescimento (DF), peso dos frutos em gramas (PF), comprimento dos frutos em $\mathrm{mm}(\mathrm{CF})$, largura dos frutos em $\mathrm{mm}(\mathrm{LF})$, espessura de casca em mm (EC), teor de sólidos solúveis totais em graus brix (SS), coloração da polpa (CP), através de uma escala de notas que seguiu a seguinte codificação: 6 - laranja; 5 - laranja-claro; 4 - ouro; 3 - amarelo; 2 - amarelo-claro, e 1 - amarelo branqueado, porcentagem de polpa (PP), peso médio de frutos em gramas (PMF).

A predição dos ganhos por índices de seleção foi fundamentada em um ideótipo. Procurou-se obter a seleção de progênies mais produtivas (maior número de frutos e produção total), com maior peso, comprimento e largura de frutos, mais precoces e com maior qualidade industrial (maior porcentagem de 
sólidos solúveis, maior porcentagem de polpa, coloração mais alaranjada e menor espessura de casca). As estimativas da predição dos ganhos por seleção, utilizando índices de seleção, foram obtidas com base nas médias do experimento, com uma porcentagem de seleção de $25 \%$, sendo selecionadas as 35 melhores progênies. Para a realização das análises estatísticas, utilizaram-se os recursos computacionais do Programa Genes (CRUZ, 2006).

Utilizaram-se os seguintes índices, conforme descritos em Cruz e Regazzi (2001): Índice de Smith (1936) e Hazel (1943): esse índice de seleção paramétrico foi concebido como uma função linear dos valores fenotípicos observados nas várias características de importância econômica, cujos coeficientes de ponderação são estimados de modo a maximizar a correlação entre o índice de seleção e o agregado genotípico. O agregado genotípico é estabelecido por outra combinação linear, envolvendo os valores genéticos, os quais são ponderados por seus respectivos valores econômicos. Índice de Pesek e Baker (1969): é um índice de seleção paramétrico, baseado nos ganhos desejados, que são mais fáceis de definir, visto que o índice é estabelecido através da definição do vetor de ganhos desejados e da matriz de variâncias e covariâncias genotípicas das variáveis envolvidas. Os coeficientes b's são o vetor $\mathrm{n} \times 1$ de coeficientes do índice calculados de acordo com a importância estabelecida pelo melhorista em sua especificação dos ganhos desejados em cada característica. Índice Clássico de Mulamba e Mock (1978): esse índice não paramétrico hierarquiza os genótipos, inicialmente, para cada característica, por meio da atribuição de valores absolutos àqueles de melhor desempenho. Por fim, os valores atribuídos a cada característica são somados, obtendo-se a soma dos "ranks", que assinala a classificação dos genótipos, ou seja, quanto menor for a soma, melhor é o desempenho de um genótipo em relação às várias características, resultando numa medida adicional. Adicionalmente, é permitido ajuste na ordem de classificação das variáveis, bastando atribuir pesos distintos a cada variável. Desta forma, tem-se: $I=p_{1} r_{1}+p_{2} r_{2}+\ldots+p_{j} r_{n} \quad$, sendo $\mathrm{p}_{\mathrm{j}}=$ peso econômico atribuído a j-ésima característica, $\mathrm{r}_{\mathrm{n}}=$ rank de um genótipo em relação à j-ésima característica. Índice da Distância Genótipo - Ideótipo (IDGI) de Cruz (2006): esse índice não paramétrico é obtido a partir das médias fenotípicas ajustadas e as distâncias euclidianas de cada indivíduo a um genótipo ideal. Segundo esse autor, considera-se nesse índice que $\mathrm{X}_{\mathrm{ij}}$ é o valor fenotípico médio do i-ésimo genótipo em relação à j-ésima característica, $Y_{i j}$, representa $o$ valor fenotípico médio padronizado e $\mathrm{C}_{\mathrm{j}}$ é uma constante relativa à depreciação da média do genótipo, por não estar dentro dos padrões desejados pelo melhorista. Estimou-se a distância Euclidiana entre o genótipo e esse ideótipo através do estimador:

$d_{j I}=\sqrt{\sum_{i=1}^{140}\left(X_{i j}-X_{I i}\right)^{2}}$, em que $\mathrm{d}_{\mathrm{jI}}=$ distância euclidiana entre o genótipo j e o ideótipo $\mathrm{I}(\mathrm{j}=1, \ldots .$. , 140), $\mathrm{X}_{\mathrm{ij}}=$ medida do caráter i no genótipo $\mathrm{j}(\mathrm{i}=1$, ......, 11), $\mathrm{X}_{\mathrm{Ii}}=$ valor definido para o ideótipo I, referente ao caráter $\mathrm{i}$.

Para a utilização dos pesos associados às estimativas dos índices, foram estimados os parâmetros genéticos via análise de variância, adotando o modelo estatístico: $\mathrm{Y}_{i j k}=\mu+r_{j}+b_{k(j)}+g_{i}+\varepsilon_{i j k}$, em que $\mathrm{Y}_{i j k}$ é a observação referente à i-ésima progênie no k-ésimo bloco, dentro da j-ésima repetição; $\mu$ é a média geral; $r j$ é o efeito da j-ésima repetição; $b_{k(j)}$ é o efeito do k-ésimo bloco, na j-ésima repetição; $g_{i}$ é o efeito da i-ésima progênie, e $\varepsilon_{i j k}$ é o erro experimental (NID, $0, \sigma^{2}$ ), sendo estimados, coeficiente de variação genético $\left(\mathrm{CV}_{\mathrm{g}}\right)$, desvio-padrão genético $\left(\mathrm{DP}_{\mathrm{g}}\right)$, índice de variação $\left(\mathrm{I}_{\mathrm{v}}\right)$ e herdabilidade no sentido amplo $\left(\mathrm{h}^{2}\right)$. Os pesos aleatórios foram atribuídos por tentativa até que se conseguissem ganhos equilibrados em todas as variáveis de interesse.

\section{RESULTADOS E DISCUSSÃO}

As Tabelas 1 e 2 contêm as estimativas dos ganhos percentuais preditos para o índice de seleção de Mulamba e Mock, índice da distância do genótipo ao ideótipo (CRUZ, 2006), índice clássico de Smith e Hazel e índice proposto por Pesek e Baker, utilizando como pesos econômicos: coeficiente de variação genético $\left(\mathrm{CV}_{\mathrm{g}}\right)$, desvio-padrão genético $\left(\mathrm{DP}_{\mathrm{g}}\right)$, índice de variaçã̃o $\left(\mathrm{I}_{\mathrm{v}}\right)$, herdabilidade $\left(\mathrm{h}^{2}\right) \mathrm{e}$ pesos aleatórios atribuídos por tentativas (PA), sendo a seleção praticada considerando os caracteres $\mathrm{DF}$, PF, CF, LF, EC, SS, CP, PP, NF, PT e PMF.

Os ganhos percentuais preditos para o índice de seleção de Mulamba e Mock, para todos os pesos econômicos, proporcionaram valores positivos para o número de frutos (NF), produção total (PT) e peso médio de fruto (PMF), simultaneamente (Tabela 1), que são os três principais caracteres. .

Para os pesos econômicos $\mathrm{I}_{\mathrm{v}}$ e $\mathrm{h}^{2}$,os ganhos foram pequenos, sobretudo para NF e PT $(1,78 \%$ a 3,70\%). Quando foi utilizado como peso econômico o $\mathrm{CV}_{\mathrm{g}}$, ocorreu ganho em PT na ordem de $6,11 \%$ e ganho em NF na ordem $7,77 \%$, sendo este o segundo maior valor entre todos os índices utilizados; porém, o ganho para PMF, apesar de ser positivo, foi baixo, com magnitude de $0,90 \%$. Cruz (2006) recomendou a utilização de estatísticas dos próprios dados experimentais como pesos para obter as ponderações 
dos índices. Para o autor, o $\mathrm{CV}_{\mathrm{g}}$ é referencial, pois é diretamente proporcional à variância genética, mantendo, de certa forma, uma proporção entre os caracteres. Outro peso econômico bastante promissor na seleção de progênies superiores foi $\mathrm{DP}_{\mathrm{g}}$, em que os ganhos para NF, PT e PMF foram de 6,70\%, $6,48 \%$ e $3,45 \%$, respectivamente. A melhor alternativa de seleção, no entanto, foi quando se utilizaram pesos aleatórios de várias grandezas. Nesse caso, após algumas simulações, conseguiu-se predizer simultaneamente ganhos elevados e equilibrados nas três principais características, sendo as magnitudes destes ganhos de 7,02\% para NF, 7,03\% para PT e 4,16\% para PMF (Tabela 1 ).

Outra observação (Tabela 1) é em relação à utilização do PA como alternativa de seleção de progênies superiores, que além de proporcionar ganhos elevados nos principais caracteres (NF, PT, $\mathrm{PP})$, possibilitou ganhos expressivos também para os outros caracteres avaliados, tais como PMF, PF e CF. Número de dias para florescimento (DF), que expressa a precocidade da progênie, apresentou ganhos preditos negativos de $-0,83 \%$. Assim, espera-se um florescimento e, consequentemente, uma produção mais precoce. Para PF, CF, LF e PP, os ganhos foram de $3,06 \%, 1,36 \%, 0,95 \%$ e $0,62 \%$, respectivamente, o que é muito importante, principalmente se o objetivo do melhoramento for contemplar o mercado in natura, cujos preços pagos ao produtor são mais atrativos, podendo ser $150 \%$ maiores que os preços pagos a frutos de classes inferiores (MELETTI et al., 2000). Para as características EC, SS e CP, os ganhos foram no sentido indesejável de melhoramento, mas os valores foram de baixa magnitude.

Gonçalves et al. (2007) avaliaram seis características produtivas de uma população de maracujáazedo, estruturada no Delineamento I de Comstock e Robinson (1948) para a estimação inicial dos parâmetros genéticos populacionais e aplicaram nesta população um ciclo de seleção utilizando diversos índices de seleção. Como resultado, os autores indicaram o índice de seleção de Mulamba e Mock, como promissor no processo de seleção de progênies superiores, pois estimou maior ganho genotípico predito.

Silva et al. (2009) estimaram, também em uma população de maracujá-azedo, os ganhos genéticos preditos por meio da seleção direta e pelo índice de seleção de Mulamba e Mock, mostrando que, em ambas as simulações de ganho (diferentes intensidades de seleção), os ganhos fundamentados no referido índice, mesmo que menores, foram expressivos e contribuíram com o processo de seleção das plantas que foram utilizadas como genitoras para a obtenção das progênies para a fase de teste da seleção recorrente.

Outro índice de seleção utilizado foi o baseado na distância do genótipo ao ideótipo (IDGI) de Cruz (2006). Os ganhos percentuais preditos para todos os pesos econômicos também proporcionaram valores positivos para NF, PT e PMF.

Assim como aconteceu para o índice de seleção proposto por Mulamba e Mock, o índice IDGI para os pesos econômicos $\mathrm{I}_{\mathrm{v}}$ e $\mathrm{h}^{2}$ proporcionou ganhos percentuais pequenos (Tabela 1). Para NF, os ganhos foram de $1,73 \%$ considerando $h^{2}$ e $1,83 \%$ considerando I como pesos, respectivamente. Para PT, os ganhos percentuais foram 3,41\% e 3,53\%, respectivamente, para $\mathrm{I}_{\mathrm{v}}$ e $\mathrm{h}^{2}$. Para PMF, o ganho percentual, considerando Iv como peso, foi de 5,21\%, sendo esta estimava a maior entre todos os quatro índices utilizados (Tabelas 1 e 2).

Outras estimativas que merecem destaque são os ganhos para PF $(5,10 \%$ e 5,05\%), CF $(2,30 \%$ e $2,24 \%)$ e LF $(1,26 \%$ e $1,25 \%)$ para os pesos econômicos I e h ${ }^{2}$, respectivamente, sendo estas também as maiores entre todos os índices utilizados. Entretanto, a utilização destes pesos econômicos não atende aos objetivos deste trabalho, pois, para dois caracteres mais importantes (NF e PT), os ganhos foram inferiores aos obtidos em outras alternativas de seleção.

$\mathrm{O}$ peso econômico $\mathrm{CV}_{\mathrm{g}}$ promoveu ganhos desejáveis em NF, PT, PMF, DF, PF, CF, LF, SS e $\mathrm{PP}$, e ganhos indesejáveis em EC e CP. Porém, estas estimativas de ganhos foram superadas quando se utilizou o peso econômico $\mathrm{DP}_{\mathrm{g}}$, em que os ganhos foram maiores em praticamente todas as características. Dessa maneira, a segunda melhor alternativa dentro deste índice foi quando se utilizou o $\mathrm{DP}_{\mathrm{g}}$ como peso econômico.

A melhor alternativa de seleção foi quando se utilizaram pesos aleatórios (PA) de várias grandezas atribuídos por tentativa. Nesse caso, conseguiu-se predizer de maneira simultânea ganhos elevados nas três principais características, sendo as magnitudes destes ganhos de 7,02\% para NF, 7,02\% para PT e $4,16 \%$ para PMF, valores estes idênticos aos obtidos na utilização do índice de Mulamba e Mock para PA.

A utilização do peso econômico aleatório, como alternativa de seleção de progênies superiores, também proporcionou ganhos no sentido desejável para as outras características avaliadas. Para as características DF, PF, CF e LF, os ganhos preditos foram de $-0,74 \%, 3,09 \%, 1,56 \%$ e $0,86 \%$, respectivamente. Por outro lado, ganhos indesejáveis de $1,34 \%,-0,58 \%,-0,67 \%$ e $-0,66 \%$ foram obtidos para as características EC, SS, CP e PP, respectivamente, o que não inviabiliza sua utilização como alternativa de 
seleção de progênies superiores para recombinação, principalmente porque essas características são de menor importância, e os ganhos, embora negativos, são muito reduzidos, não alterando significativamente a média populacional.

Com a utilização do índice de seleção proposto por Smith e Hazel, foi possível prever pequenos ganhos simultâneos nas principais características, para os pesos econômicos $I_{v}$ e $h^{2}$ (Tabela 2). Para os pesos econômicos $\mathrm{CV}_{\mathrm{g}}, \mathrm{DP}_{\mathrm{g}}$ e $\mathrm{PA}$, os ganhos para PMF foram negativos $(-1,34 \%,-1,95 \% \mathrm{e}-0,31 \%$, respectivamente), sendo é uma situação não desejável. Quando o peso econômico foi PA, os ganhos previstos para NF e PT $(5,93 \%$ e $4,53 \%$, respectivamente $)$ foram as melhores alternativas de ganho dentro deste índice, embora quando comparados com os outros índices não paramétricos, como o de Mulamba e Mock e o IDGI, estes pesos, baseados em parâmetros genéticos, podem ser descartados.

As piores alternativas de ganhos genéticos preditos foram obtidas com a utilização do índice de Smith e Hazel (Tabela 2). Em todas as alternativas de seleção baseada nesse índice, foram observados ganhos negativos para algumas características avaliadas. Além disso, nas variáveis em que os ganhos genéticos preditos foram favoráveis ao melhoramento do maracujazeiro-azedo, estes foram de baixa magnitude. Portanto, a utilização deste índice com os pesos econômicos associados a ele não proporcionariam ganhos desejáveis em relação às características estudadas, inviabilizando sua utilização aos propósitos deste trabalho. O mesmo resultado foi observado por Gonçalves et al. (2007), segundo os quais, o índice de Smith e Hazel foi também o que apresentou o menor ganho predito nas diversas alternativas de seleção, em comparação com outros índices. Este índice também foi avaliado por Oliveira et al. (2008), apresentando ganhos genéticos preditos negativos em relação às características rendimento de polpa e formato de fruto, embora tenha demonstrado a possibilidade de obtenção de maiores ganhos na característica número de frutos.

Os ganhos genéticos percentuais preditos para o índice de seleção de Pesek e Baker, expostos na Tabela 2, demonstraram que, para os pesos econômicos $\mathrm{CV}_{\mathrm{g}}, \mathrm{I}_{\mathrm{v}}, \mathrm{h}^{2} \mathrm{e} \mathrm{PA}$, os ganhos previstos foram análogos para todas as características, sugerindo que os valores não foram discrepantes o suficiente para causar mudanças nos ganhos genéticos. A utilização destes pesos econômicos permitiu ganhos equilibrados e positivos para as três principais características avaliadas (NF, PT e PMF). Entretanto, estes ganhos foram menores do que os obtidos quando se utilizou do procedimento de Mulamba e Mock e a distância do genótipo ao ideótipo (IDGI). Além disso, a utilização destes pesos econômicos promoveu ganhos indesejáveis para DF, EC, SS, CP e PP, ou seja, a seleção fundamentada nestes pesos promoveu ganhos genéticos negativos para teor de sólidos solúveis, para coloração e porcentagem de polpa, e ganhos positivos para espessura da casca e dias até o florescimento. Os ganhos para PF, CF e LF são aceitáveis, mas, no entanto, outras alternativas em que se utilizaram os índices não paramétricos foram mais interessantes por promoverem maiores ganhos genéticos para esses caracteres.

Quando se utilizou o peso econômico do DP no índice de Pesek e Baker, o ganho genético para $\mathrm{NF}$ foi de $8,07 \%$, sendo a maior estimativa encontrada em todas as alternativas avaliadas. $\mathrm{O}$ ganho para $\mathrm{PT}$ também foi positivo e alto $(5,11 \%)$, mas menor do que os estimados quando se utilizaram os índices de Mulamba e Mock e da distância genótipo-ideótipo nos pesos econômicos $\mathrm{CV}_{\mathrm{g}}$, DP $\mathrm{g}$ e PA. Por outro lado, o peso econômico DP ${ }_{g}$ no índice de Pesek e Backer gerou ganhos negativos em quase todas as características avaliadas (PF, CF, LF, SS, CP e PP), além de PMF, que é considerada muito importante $(-2,33)$, o que praticamente inviabiliza a utilização do peso $\mathrm{DP}_{\mathrm{g}}$ dentro do referido índice como estratégia de seleçẵo.

Contrariamente, no trabalho de Gonçalves et al. (2007), o índice de Pesek e Backer foi eficaz na escolha das melhores progênies para recombinação e apresentou ganhos de $15,92 \%$ para NF; $0,05 \%$ para PF; $0,17 \%$ para CF; $0,48 \%$ para $L F ; 0,92 \%$ para EC; e $2,75 \%$ para DF. Neste trabalho, os autores visaram a obter ganhos em NF próximos ao patamar do ganho direto, que foi de $18,5 \%$, sem que ocorresse queda nas outras características. Oliveira et al. (2008), utilizando o mesmo índice, obtiveram ganhos de $-4,32 \%$ para PF; $9,54 \%$ para rendimento de polpa (RP); $-4,72 \%$ para CF; $-2,01 \%$ para $\mathrm{LF} ;-3,7 \%$ para o formato do fruto, e $-0,19 \%$ para número de frutos. Dessa maneira, ganhos no sentido desejado ocorreram apenas para RP, sendo que o índice não foi recomendado pelos autores por ter apresentado o pior desempenho quando comparado com outros utilizados.

Apesar do uso dos índices, alternativas de seleção direta para esses mesmos caracteres foram avaliadas por Moraes et al. (2005), em que os autores obtiveram ganhos de $36,6 \%$ para produção de frutos, 35,9\% para número de frutos e 10,7\% para peso médio de frutos. No entanto, cabe ressaltar que estes valores foram obtidos para seleção truncada e que esses caracteres apresentaram correlações genéticas de baixa magnitude e sinal negativo, tais 
como peso médio de fruto e número de frutos no valor de -0.001 . Isto reforça a utilização de índices de seleção, que permitem ganhos equilibrados e bem distribuídos mesmo para caracteres que apresentam correlação negativa.

Após analisar a possibilidade de utilização das várias alternativas de seleção, os índices baseados na soma de ranks de Mulamba e Mock e na distância entre o genótipo e o ideótipo (CRUZ, 2006), com pesos aleatórios atribuídos por tentativas, permitiram ganhos superiores e mais bem distribuídos entre as principais características e também ganhos expressivos nas características PF, CF, LF e DF. Por conseguinte, a opção da seleção das 35 progênies superiores foi feita com base no índice de Mulamba e Mock, já que apresentou ganhos ligeiramente superiores em cinco das oito características secundárias consideradas. Vale ressaltar que esta pequena vantagem se deve, provavelmente, a uma única progênie, já que quando se comparam as progênies selecionadas pelos dois índices, a coincidência foi de 97,5\%, ou seja, apenas uma progênie foi selecionada por um método e não foi para o outro. Dessa forma, fundamentado na soma de ranks, foi possível selecionar, simultaneamente, progênies superiores para NF, PT, PMF, DF, PF, CF, LF e PP, dando possibilidade de prosseguimento do programa em execução com previsão de ganhos genéticos satisfatórios e bem equilibrados em diversas características como NF, PT, PMF e PF.

TABELA 1 - Estimativas dos ganhos percentuais por seleção simultânea, em onze características avaliadas em progênies de irmãos completos, em maracujazeiro, referentes ao segundo ciclo de seleção recorrente intrapopulacional, de acordo com os índices de Mulamba e Mock e Distância Genótipo-Ideótipo, utilizando os pesos econômicos CV, DP, I $\mathrm{h}^{2} \mathrm{e}$ PA.

\begin{tabular}{c|ccccc|ccccc}
\hline \multirow{2}{*}{$\begin{array}{c}\text { Características } \\
(1)\end{array}$} & \multicolumn{5}{|c|}{ Mulamba e Mock } & \multicolumn{5}{c}{ Distância Genótipo-Ideótipo } \\
\cline { 2 - 11 } & $\mathrm{CV}_{\mathrm{g}}^{(2)}$ & $\mathrm{DP}_{\mathrm{g}}$ & $\mathrm{Iv}$ & $\mathrm{h}^{2}$ & $\mathrm{PA}$ & $\mathrm{CV}_{\mathrm{g}}$ & $\mathrm{DP}_{\mathrm{g}}$ & $\mathrm{Iv}$ & $\mathrm{h}^{2}$ & $\mathrm{PA}$ \\
\hline DF & $-1,48$ & $-1,28$ & $-0,88$ & $-0,93$ & $-0,83$ & $-0,98$ & $-0,79$ & $-0,14$ & $-0,10$ & $-0,74$ \\
$\mathrm{PF}$ & 1,33 & 3,66 & 4,61 & 4,26 & 3,06 & 2,43 & 3,89 & 5,10 & 5,05 & 3,09 \\
$\mathrm{CF}$ & 0,92 & 1,60 & 2,24 & 2,18 & 1,36 & 1,18 & 1,50 & 2,30 & 2,24 & 1,56 \\
LF & 0,34 & 1,08 & 1,30 & 1,20 & 0,95 & 0,76 & 1,09 & 1,26 & 1,25 & 0,86 \\
EC & $-1,41$ & 2,02 & $-0,24$ & $-0,62$ & 1,29 & 1,44 & 1,99 & 1,74 & 1,54 & 1,34 \\
SS & 0,09 & $-0,64$ & 0,42 & 0,36 & $-0,65$ & 0,18 & $-0,25$ & 0,56 & 0,66 & $-0,58$ \\
CP & 0,08 & $-0,35$ & $-0,01$ & 0,02 & $-0,61$ & $-0,12$ & $-0,53$ & $-0,01$ & $-0,04$ & $-0,67$ \\
PP & 2,75 & $-0,51$ & 1,42 & 1,79 & 0,62 & 1,23 & $-0,15$ & 0,99 & 1,10 & $-0,66$ \\
NF & 7,77 & 6,70 & 1,98 & 2,35 & 7,02 & 5,54 & 6,29 & 1,83 & 1,73 & 7,02 \\
PT & 6,11 & 6,48 & 3,54 & 3,70 & 7,03 & 5,82 & 6,47 & 3,53 & 3,41 & 7,02 \\
PMF & 0,90 & 3,45 & 5,17 & 4,72 & 4,16 & 3,91 & 4,19 & 5,21 & 5,06 & 4,16 \\
\hline
\end{tabular}

(1) $\mathrm{DF}=$ número de dias para o florescimento, $\mathrm{PF}=$ peso de fruto, $\mathrm{CF}=$ comprimento de fruto, $\mathrm{LF}=$ largura de fruto, $\mathrm{EC}=$ espessura de casca, $\mathrm{SST}=$ teor de sólidos solúveis totais, $\mathrm{CP}=$ cor da polpa, $\mathrm{PP}=$ peso da polpa, $\mathrm{NF}=$ número total de frutos, $\mathrm{PT}=$ produção total em ton/ha, PMF = peso médio de fruto. ${ }^{(2)} \mathrm{CV}_{\mathrm{g}}=$ coeficiente de variação genético; $\mathrm{DP}=$ desvio-padrão genético; $\mathrm{I}_{\mathrm{v}}=$ índice de variação; $h^{2}=$ herdabilidade e PA $=$ Pesos aleatórios atribuídos por tentativas $(1,200,200,200,1,1,1,200,1.000,1.000,1.000)$.

TABELA 2 - Estimativas dos ganhos percentuais por seleção simultânea, em onze características avaliadas em progênies de irmãos completos, em maracujazeiro, referentes ao segundo ciclo de seleção recorrente intrapopulacional, de acordo com os índices de Smith e Hazel, e Pesek e Baker, utilizando os pesos econômicos CV, DP, I $\mathrm{h}^{2} \mathrm{e}$ PA.

\begin{tabular}{c|ccccc|ccccc}
\hline \multirow{2}{*}{$\begin{array}{c}\text { Características } \\
(1)\end{array}$} & \multicolumn{4}{|c|}{ Smith e Hazel } & \multicolumn{4}{c}{ Pesek e Baker } \\
\cline { 2 - 10 } & $\mathrm{CV}^{(2)}$ & $\mathrm{DP}$ & $\mathrm{IV}$ & $\mathrm{h}^{2}$ & $\mathrm{PA}$ & $\mathrm{CV}$ & $\mathrm{DP}$ & $\mathrm{IV}$ & $\mathrm{h}^{2}$ & $\mathrm{PA}$ \\
\hline DF & $-2,23$ & $-2,21$ & $-1,60$ & $-1,62$ & $-2,01$ & 0,97 & $-1,22$ & 0,97 & 0,97 & 0,97 \\
PF & $-1,62$ & $-2,29$ & 2,49 & 2,51 & $-1,25$ & 2,39 & $-2,42$ & 2,39 & 2,39 & 2,39 \\
CF & $-0,63$ & $-1,22$ & 1,53 & 1,55 & $-0,48$ & 1,29 & $-0,98$ & 1,29 & 1,29 & 1,29 \\
LF & $-0,15$ & $-0,34$ & 0,62 & 0,66 & $-0,08$ & 0,60 & $-0,25$ & 0,60 & 0,60 & 0,60 \\
EC & $-0,66$ & $-1,17$ & 1,26 & 1,17 & $-0,57$ & 2,10 & $-1,35$ & 2,10 & 2,10 & 2,10 \\
SS & $-1,32$ & $-1,24$ & $-0,76$ & $-0,71$ & $-1,99$ & $-1,69$ & $-2,17$ & $-1,69$ & $-1,69$ & $-1,69$ \\
CP & $-0,67$ & $-0,93$ & $-0,93$ & $-0,96$ & $-0,87$ & $-1,44$ & $-0,96$ & $-1,44$ & $-1,44$ & $-1,44$ \\
PP & $-0,16$ & 0,78 & $-1,56$ & $-1,27$ & 0,93 & $-1,41$ & $-0,12$ & $-1,41$ & $-1,41$ & $-1,41$ \\
NF & 2,33 & 3,52 & 0,68 & 0,74 & 5,93 & 4,04 & 8,07 & 4,04 & 4,04 & 4,04 \\
PT & 1,74 & 2,26 & 2,63 & 2,64 & 4,53 & 4,93 & 5,11 & 4,93 & 4,93 & 4,93 \\
PMF & $-1,34$ & $-1,95$ & 4,23 & 4,13 & $-0,31$ & 4,56 & $-2,33$ & 4,56 & 4,56 & 4,56 \\
\hline
\end{tabular}

(1) $\mathrm{DF}=$ número de dias para o florescimento, $\mathrm{PF}=$ peso de fruto, $\mathrm{CF}=$ comprimento de fruto, $\mathrm{LF}=$ largura de fruto, $\mathrm{EC}=$ espessura de casca, $\mathrm{SST}=$ teor de sólidos solúveis totais, $\mathrm{CP}=$ cor da polpa, $\mathrm{PP}=$ peso da polpa, $\mathrm{NF}=$ número total de frutos, $\mathrm{PT}=$ produção total em ton/ha, PMF = peso médio de fruto. ${ }^{(2)} \mathrm{CV}_{\mathrm{g}}=$ coeficiente de variação genético; $\mathrm{DP}=$ desvio-padrão genético; $\mathrm{I}_{\mathrm{v}}=$ índice de variação; $\mathrm{h}^{2}=$ herdabilidade e PA $=$ Pesos aleatórios atribuídos por tentativas $(1,200,200,200,1,1,1,200,1.000,1.000,1.000)$ 


\section{CONCLUSÕES}

Os índices multivariados não paramétricos com pesos aleatórios atribuídos por tentativas estimaram ganhos superiores e de forma equilibrada para todos os caracteres em relação aos os índices paramétricos. Utilizando-se dessa estratégia, é possível a seleção de progênies superiores para dar prosseguimento ao programa de seleção recorrente intrapopulacional em desenvolvimento, aplicando-se o índice de seleção proposto por Mulamba e Mock.

\section{REFERÊNCIAS}

ALBUQUERQUE, A. S.; BRUCKNER, C. H.; CRUZ, C. D.; CASALI, V. W. D.; ARAÚJO, R. C.; SOUZA, J. A. Possibilidade de seleção indireta para peso do fruto e rendimento em polpa em maracujá (Passiflora edulis Sims.). In: CONGRESSO BRASILEIRO DE FRUTICULTURA, 17., 2002, Belém. Anais...

CRUZ, C. D. Programa genes: biometria. Viçosa: UFV, 2006. v.1, 382 p.

CRUZ, C. D.; REGAZZI, A. J. Modelos biométricos aplicados ao melhoramento genético. 2.ed. Viçosa: UFV, 2001. 390 p.

FREITAS JÚNIOR, S. de P.; AMARAL JÚNIOR, A. T. do; RANGEL, R. M.; VIANA, A. P. Genetic gains in popcorn by full-sib recurrent selection. Crop Breeding and Applied Biotechnology, Londrina, v. 9, p. 1-7, 2009.

GARCIA, A. A. F.; SOUZA JÚNIOR, C. L. de. Comparação de índices de seleção não paramétricos para a seleção de cultivares. Bragantia, Campinas, v.58, p.253-267, 1999.

GONÇALVES, G. M.; VIANA, A. P.; BEZERRA NETO, F. V.; PEREIRA, M. G.; PEREIRA, T. N. S. Seleção e herdabilidade na predição de ganhos genéticos em maracujá-azedo. Pesquisa Agropecuária Brasileira, Brasília, v.42, n.2, p.235-240, 2007.

IBGE - Instituto Brasileiro de Geografia e Estatística. Quantidade produzida, valor da produção, área plantada e área colhida da lavoura permanente. Disponível em: <http://www.sidra.ibge.gov.br $>$. Acesso em: 22 out. 2010.
MELETTI, L. M. M.; SANTOS, R. R. dos; MINAMI, K. Melhoramento do maracujazeiro-azedo: obtenção do composto IAC-27. Scientia Agricola, Piracicaba, v. 56, p. 491-498, 2000.

MORAES, M.C.; GERALDI, I.O.; MATTA, F.P.; VIEIRA, M.L.C. Genetic and phenotypic parameter estimates for yield and fruit quality traits from a single wide cross in Yellow Passion Fruit. HortScience, Alexandria, v.40, n.7, p.1978-1981, 2005.

OLIVEIRA, E. J.; SANTOS, V. S.; LIMA, D. S.; MACHADO, M. D.; LUCENA, R. S.; MOTTA, T. B. N.; CASTELLEN, M. S. Seleção em progênies de maracujazeiro-amarelo com base em índices multivariados. Pesquisa Agropecuária Brasileira, Brasília, v. 43, n. 11, p. 1543-1549, 2008.

PEDROZO, C. A.; BENITES, F. R. G.; BARBOSA, M. H. P.; RESENDE, M. D. V.; SILVA, F. L. Efi-ciência de índices de seleção utilizando a metodologia reml/blup no melhoramento da cana-de-açúcar. Scientia Agrária, Piracicaba, v. 10, p. 31-36, 2009.

SILVA, M. G. M.; VIANA, A. P.; GONCALVES, G. M.; AMARAL JUNIOR, A. T.; PEREIRA, M. G. Seleção recorrente intrapopulacional no maracujazeiro-amarelo: Alternativa de capitalização de ganhos genéticos. Ciência e Agrotecnologia, Lavras, v. 33, p. 170-176, 2009.

TARDIN, F. D.; PEREIRA, M. G.; GABRIEL, A. P. C.; AMARAL JÚNIOR, A. T. do; SOUZA FILHO, G. A. de. Selection index and molecular markersin reciprocal recurrent selection in maize. Crop Breeding and Applied Biotechnology, Londrina, v. 7, p. 225-233, 2007.

VASCONCELOS, E. S.; REIS, M. S.; SEDYIAMA, T.; CRUZ, C. D. Análise não paramétrica da sanidade de sementes e índices de eliminação e classificação de genótipos de soja. Pesquisa Agropecuária Brasileira, Brasília, v. 43, n. 3, p. 341-348, 2008.

VIANA, A. P.; PEREIRA, T. N. S.; PEREIRA, M. G.; SOUZA, M. M. de; MALDONADO, J. F. M.; AMARAL JÚNIOR, A. T. do. Simple and canonic correlation between agronomical and fruit quality traits in yellow passion fruit (Passiflora edulis $f$. flavicarpa) populations. Crop Breeding and Applied Biotechnology, Viçosa, MG, v. 3, n. 2, p. 133-140, 2003 